\title{
DIREITO E LITERATURA: UMA INTERSECÇÃO POSSÍVEL? INTERLOCUÇÕES COM O PENSAMENTO WARATIANO
}

\author{
Albano Marcos Bastos PêPe ${ }^{1}$
}

\begin{abstract}
RESUMO: O texto, além de postular a necessidade de aproximação do discurso jurídico ao discurso literário, resgata a importância de Luis Alberto Warat como fundador dos estudos de Direito e Literatura no Brasil e, recorrendo ao artifício de uma entrevista "fantasmática", oferece uma síntese do pensamento waratiano sobre as possibilidades de interlocução entre o direito e a literatura.
\end{abstract}

Palavras-Chave: Luis Alberto Warat; discurso jurídico; narrativa literária; epistemologia das significações.

O Direito tem sido, ao longo dos últimos anos, uma área de estudo de diversos campos do conhecimento, sejam eles científicos ou não: da Ciência Política, da Sociologia, da Filosofia, da Linguística, assim como da literatura em suas narrativas, resultado da imaginação criativa de seus criadores, derivadas de nossa diversificada formação cultural. Especificamente no âmbito da literatura, o discurso jurídico, assim como seus atores, se faz presente já nos textos gregos clássicos. Sófocles e Aristófanes são exemplos de autores de narrativas que tratam de julgamentos, de penalidades e dos ideais de justiça derivados da antiga tradição jurídica ocidental, como é o caso exemplar de Antígona e de As vespas. Na modernidade clássica, temos personagens da obra de Shakespeare, que são objeto de nossas reflexões e pesquisas, como é o caso do enredo do Mercador de Veneza, dentre outros. Outros exemplos estão nas novelas de fins do século XIX. Nelas, encontramos Dostoiévski em Crime e castigo e Tolstoi em A morte de Ivan Ilich. Na literatura brasileira, temos Machado de Assis e Graciliano Ramos, dentre tantos que se inspiraram nos mundos possíveis do discurso jurídico.

1 Doutor em Direito pela Universidade Federal do Paraná (UFPR). Santa Maria, RS, Brasil. CV Lattes: http://lattes.cnpq.br/7001963983916929. E-mail: pepeamb48@gmail.com. 
Esses são apenas pequenos exemplos da ausência de fronteiras rígidas entre o discurso jurídico, seu pretenso estatuto de cientificidade, e as narrativas literárias, frutos da criatividade imagética de escritores e poetas. Não somos herdeiros da República Platônica, portanto não expulsamos os nossos poetas e narradores. Convivemos esteticamente com sua poiesis e seu fazer criativo, que nos desvela existenciais e mundos. Contraditoriamente, convivemos com o crescente controle da sociedade por tecnologias e técnicas de formatação da existência humana. A nós interessa neste momento, destacar uma maior judicialização do cotidiano, sufocado pelas estruturas jurídicas, manifestas em suas regras, doutrinas e jurisprudências e cristalizadas pelos institutos que criam, aplicam e ensinam o direito. Posso até dizer que tal monopólio de racionalização judicial dificulta o exercício efetivo da cidadania pressuposto pelas Constituições democráticas. É como se ficássemos cada vez mais distantes das autonomias institucionais, limitados a sermos tão somente meros jurisdicionados sob a tutela de um Estado de Direito totalitário, pressuposto por Hobbes em seu Leviatã.

Estudos, pesquisas, publicações e seminários têm acontecido nos meios acadêmicos abordando tais constatações. Podemos verificar que eles indicam algo de novo acontecendo na recepção do discurso jurídico pela literatura. Recepcionada por muitos com certo ceticismo e por poucos com muito entusiasmo, importa salientar que seja uma difícil caminhada aproximar critica e reflexivamente a narrativa literária e a formatação descritiva e prescritiva apresentada pelo discurso jurídico. A narrativa literária está relacionada, diríamos, a uma forma de racionalidade que Habermas denominaria estético expressiva; enquanto que o direito tem pretensões de situar-se no campo de uma racionalidade instrumental e estratégica. Embora para Habermas o campo de racionalidade pressuposto para o direito seja o de uma racionalidade prático-moral. Sem entrar no mérito dessa questão, sabemos que o legado jurídico está fundamentado nos princípios da validade formal de seus enunciados, assim como na eficácia de sua aplicação, marca de uma racionalidade instrumental e estratégica.

Estudos e publicações de uma possível aproximação entre o direito e literatura foram iniciados em fins dos anos 70 pelo jusfilósofo argentino- 
baiano (como ele costumava denominar-se) Luís Alberto Warat, no início de sua trajetória em universidades brasileiras. Warat já trazia da Argentina uma vasta bagagem de conhecimento sobre as relações entre tais campos das formações discursivas. Leitor assíduo de autores como Jorge Luis Borges, Julio Cortázar e Manoel Puig, acrescentou à sua biblioteca autores brasileiros como Jorge Amado e Mário de Andrade. Personagens de alguns desses autores emergiam no seu pensamento quando tratava de relações possíveis entre a literatura e a tradição jurídica. Alguns deles como os famas e os cronópios, das Histórias de Famas e Cronópios, de Cortázar (Warat, 1994-1997); assim como Dona Flor, Vadinho e Teodoro, de Dona Flor e os seus dois maridos, de Amado (Warat, 1985), passaram a compor os textos surrealistas criados por Warat na produção de um clima, de um ambiente, de uma atmosfera (Stimmung), onde direito e literatura se aproximavam a cada reflexão, a cada página de areia - relembrando Borges - , que dialeticamente se fazia e se desfazia.

Na construção de uma linguagem que se inscrevia no âmbito das narrativas de um Realismo Mágico, Warat convidou para sentar, à sua mesa, pensadores como André Breton, Roland Barthes e Mikhail Bakhtin e, com tais interlocutores, incluiu campos de significações que se abriam para o surrealismo, para a carnavalização, para a semiologia transgressora (Warat, 1988). Portanto, posso afirmar que ele inaugurou, no Brasil, esse movimento extremamente fecundo de diálogos e aproximações da literatura com os textos jurídicos. As sementes lançadas se expandiram ao longo do tempo, rizomaticamente, agregando novas narrativas, novos leitores e novos interlocutores.

Constata-se que no cotidiano dos cursos jurídicos surgem novas interlocuções, cada vez mais fecundas, abrindo caminhos criativos nessa seara. Direito e Literatura, enquanto disciplina curricular, frequenta cada vez mais o quadro de matérias dos cursos jurídicos. Podemos, inclusive, pensar que a prática jurídica cotidiana pode também ser também atravessada por novas narrativas, assimiláveis nos processos reflexivos das autonomias, das singularidades e das alteridades, tão necessários em um cotidiano cada vez mais judicializado.

O judiciário, em seu dia a dia, estabelece limites pontuais em torno de pilares tão conhecidos por aqueles que frequentam seus corredores, seus 
gabinetes e suas instâncias. Ali, respira-se o ar de seus mitos, de seus ritos e de seus símbolos. Ali, os operadores do direito disciplinada e pontualmente burocratizam os interesses, os conflitos e as aspirações de uma sociedade normalmente conflitiva, cada vez mais dependente das decisões resultantes de processos e de decisões tornadas judiciais que se arrastam ao longo do tempo. Adentrar com demandas no judiciário significa, para o cidadão, perder o controle dos seus conflitos, interesses e singularidades. Assim como as autonomias, são deixados de lado, como se não mais existissem, as identidades históricas dos atores sociais, que ficam prisioneiras do poder coercitivo do Estado. As narrativas são transformadas em depoimentos pontuais e anotados burocraticamente pelos escribas oficiais. O campo polissêmico, fruto de experiências narradas pelo depoente, fica reduzido aos limites do corpo do processo, descartados os sentimentos e os afetos que ofereciam condições de sentido ao que era narrado, tanto pela possível vítima como pelo possível transgressor. Os autos do processo se autonomizam e se distanciam dos envolvidos. Essa é a dimensão kafkiana do processo. Aos jurisdicionados, cabe tão somente acompanhar de longe, através de seus advogados, o penoso trajeto nos labirintos do Poder Judiciário, para eles desde sempre incompreensível.

À diferença dos textos da narrativa literária - ricos na produção de linguagens metafóricas e que produzem aportes voltados para o realismo mágico das narrativas, ao tratar de temas existenciais e, portanto, polissêmicos -, o discurso jurídico é estruturado a partir de uma matriz positivista, ou seja, cientificista. Uma de suas características é a da redução racionalizadora de seus argumentos, limitados à pretensão racional de seus paradigmas, ditos dogmáticos e "científicos". Warat, dentre outras abordagens, denominava tal pretensão de "pensamento único". Para ele, este seria responsável pelo legado "de uma linguagem racionalizadora do status quo, que, como digno filho do paradigma moderno, identifica o real com a pomposa racionalidade moderna e encobre as contradições e conflitos presentes nessa realidade disfarçada de eficácia e crescimento" (Warat, 2004). Poderíamos afirmar que as pretensões de legalidade e de legitimidade dos enunciados normativos encontraram no "cientificismo" as bases de sustentação para as afirmações atinentes às questões da validade $\mathrm{e}$ da eficácia do direito. 
Nesse sentido, validade e eficácia gravitam em torno daquilo que foi consagrado como a dogmática jurídica. Conforme Warat, as proposições da dogmática jurídica se fundamentam em um trabalho da lógica e da técnica jurídicas voltadas para a realização de operações de análise e síntese, assim como de deduções e induções voltadas para a construção uma série de conceitos e princípios objetivados numa interpretação clara das regras legais integrantes do direito positivo. Tal racionalidade técnica, operacionalizada através de um método técnico jurídico ou, se quisermos, lógico-abstrato, é determinada pela dogmática jurídica como único método possível no estudo da Ciência jurídica.

Creio que assim adentramos no cerne do discurso jurídico enquanto realização do método dogmático. Ainda seguindo a argumentação waratiana e visando o desvelamento dos véus ideológicos do direito, ele apresenta, em sua Introdução geral ao direito, a dogmática tradicional a partir de três etapas de aplicação e seu método técnico jurídico (Warat, 1994-1997):

1 A primeira etapa compreende a época da conceitualização dos textos legais, que se baseia no pressuposto de que não há mais direito do que o ordenamento jurídico estabelecido através das leis validamente editadas e vigentes. Desse modo, a dogmática jurídica se vincula diretamente com o positivismo, limitando sua função à interpretação da lei.

2 A segunda etapa é propriamente a da dogmatização jurídica, da fixação dos dogmas jurídicos, da elaboração das proposições, categorias e princípios obtidos a partir de conceitos jurídicos extraídos os textos legais.

3 A terceira etapa da dogmática jurídica se caracteriza pela sistematização, chegando assim à meta perseguida pela ciência de matriz positivista, que é a constituição de uma disciplina específica, objeto de conhecimento, em um sistema.

Com tal estruturação, o discurso jurídico se apoia em suas intervenções no tecido social, garantindo ao Estado sua força coercitiva amparada na legalidade. Assim sendo, os juristas acreditam na cientificidade de sua produção teórica específica. Ao produzir uma rígida rede que significações, o direito não se permite atravessamentos sejam eles de qualquer ordem. Daí entendermos a proposta waratiana de transgressão 
dos limites do discurso jurídico oficial e acadêmico. A partir da epistemologia das significações, elabora, no meu entendimento, uma nova postura hermenêutica, encontrando na literatura e na psicanálise o Stimmung provocador e criativo para a compreensão dos efeitos do discurso jurídico no mundo jurisdicionado em que vivemos.

À guisa de uma provisória conclusão:

Assim como Jorge Amado deu voz e materialidade diáfana para Vadinho em sua obra, pretendendo dar um toque surreal a esta narrativa e convido Luis Alberto Warat para uma surreal interlocução sobre o direito e a literatura:

Albano - Caro Amigo, gostaria que me falasses sobre questões atinentes ao discurso jurídico e à narrativa literária. Começaria te perguntando sobre o que caracterizas como uma epistemologia das significações quando tratas do discurso jurídico?

Warat - O conhecimento conceitual do direito é incapaz de explicar os efeitos sociais e as reações política que ele pode provocar e que só podem ser compreendidos através do ponto de vista epistemológico que proponho denominar epistemologia das significações. Trata-se de uma tentativa de constituição de um plano reflexivo que, negando a Identidade entre o conceito e a significação, se forçaria como estabelecer uma análise discursiva capaz de nos mostrar as dimensões referenciais ou conotativas dos diferentes tipos de enunciação efetuados na práxis do direito. Pretendo partir dessa problemática para tentar situar o processo de produção do conhecimento crítico do direito como uma modalidade epistemológica até agora ausente, e não como teoria alternativa sobre o direito e a sociedade.

Albano - Então, sua proposta é a de discorrer sobre o distanciamento entre a pretensão do conhecimento conceitual do direito e realidades existentes no mundo da vida, portanto...

Warat - Em verdade, a ciência do direito que os juristas invocam em suas práticas profissionais é uma "doxa" metódica e sistemática, o conjunto de opiniões de ofício, ou seja, uma prática discursiva fundamentalmente determinada por hábitos semiológicos e costumes 
intelectuais, enfim, estamos reivindicando um saber crítico do direito como um novo ponto de vista epistemológico que tem por objeto de análise os discursos competentes da ciência e epistemologia jurídicas. Ditos discursos competentes são forjados na própria práxis jurídica, que temos denominado "sentido teórico dos juristas". Metaforicamente, caracterizamos o sentido comum teórico como uma caravana de ecos legitimadores que tem um conjunto de crenças a partir do qual podemos dispensar ou aprovar o fundamento das condições e das relações que tais crenças mitificam.

Entendo que esse é um embate a ser desenvolvido no campo das legitimações entendidas pelo discurso oficial do direito. No entanto, poderíamos deslocar essa discussão para a tentativa de superação dos estereótipos produzidos por tais concepções de mundo.

Albano - Que atravessamentos poderíamos esperar com a contribuição da literatura e de suas narrativas a uma possível recepção do discurso jurídico?

Warat - Os homens estão repletos de estereotipações, das versões singulares e lineares que lhe são impostas, e não há espaços dentro deles para criatividade e autonomia, para a compreensão não oficial dos sentidos, o que viria a constituir o plural de significações. A semiologia dominante, apelando para a linguagem, estabelece modelos do desejo, neles gozar é igual a possuir. Por meio desses modelos, o homem não só aceita as hierarquias como também aprende a amá-las. Todos somos proprietários burgueses dos nossos desejos, todos ajudamos a manter a ilusão de uma realidade imóvel. A forma mais ousada de substituir a participação pelo olhar é a da reflexividade da ciência. Nessa forma de compreensão, a lógica provoca o grande tabu, admitindo linguagens exteriores umas às outras. Frente a tudo isso, apelo à fantasia, para fecundar o real e os seus símbolos.

Albano - Na estória de Dona Flor, volta à sua vida a figura de Vadinho, que magicamente estabelece um lado surreal na narrativa de Jorge Amado. O que representa o retorno de Vadinho no jogo das significações simbólicas? 
Warat - O retorno de Vadinho é o símbolo de como, pelo fantástico, podemos manter uma relação adúltera com o real. É o marido sem o espírito da legalidade que a mulher sonha ter, para temperar alquimia de ternura e segurança do desejo instituído. A redescoberta da paixão pela vida, da paixão de compreender os outros, virá de um confronto com os desejos que fluem marginalmente. A marginalidade é um lugar de recuperação das relações livres com os desejos. Ali é onde encontramos o sangue quente e o esperma urgente. Seu retorno é o símbolo de como, pelo fantástico, podemos manter uma relação adúltera com o real. É o marido sem o espírito da legalidade que a mulher sonha ter, para temperar alquimia de ternura e segurança do desejo instituído.

A volta de Vadinho permite a Dona Flor romper os ímpetos do desejo com o dever, aceitando o adultério como condição natural do casamento. Dona Flor termina agitando-se dentro de um imaginário logo-mítico, ficando bem casada, com uma ordem sólida de conceitos e encantamentos; adúltera, com o devir malandro espontâneo, daí as significações vagabundas dos sentidos ao vento e despenteados, dos sentidos democráticos.

Albano - O que sinalizarias para o mundo jurídico em suas formações conceituais e existenciais onde o desejo é silenciado?

Warat - Quero propor aos juristas em geral que aceitem um discurso dito do lugar mais indefinido que a linguagem tolere: novelas, poemas e desejos, para que eles entrem e invadam a totalidade dos discursos das ciências sociais ou metafísicas; que nasçam na mesa de um bar, numa cama, nesse depois cheio de distinção e carinho; servindo com a mesma eficiência que as verdades instituídas, para escolher significações para o mundo. Devemos minar a linguagem jurídica para aprender que o direito também é o espelho da irracionalidade humana. A justiça também é o teatro do absurdo.

Albano - Enfim, qual o papel da linguagem enquanto produtora, também, de transgressões?

Warat - Temos que reinventar a língua. Para isso é preciso recuperar o lugar da linguagem que está em nosso próprio corpo e com ele iniciarmos uma crítica. 
Inaugurar territórios de ambiguidades é o que pretendo com essa escritura, já que sinto a necessidade de pulverizar-me como um sujeito acadêmico de enunciação. Daí a importância de por à vontade meu prazer pela escritura escapando a três grandes fantasmas: a estereotipação, a analogia e o mito da unidade. Transgredindo permanentemente - nessa expedição pelo saber dos juristas e dos demais sociolóides - as deformações regradas da semântica cientificista.

Albano - Gostaria que me falasses sobre a importância de Barthes, de Bakhtin e do surrealismo bretoniano para esta cruzada, algo quixotesco não achas?

Warat - Meu encantamento por Barthes deve-se em primeiro lugar à possibilidade que sua obra me dá para pensar o mundo como uma pluralidade infinita de significações; segundo, porque suas crônicas do imaginário me permitem situar a verdade como uma de suas dimensões. Depois porque convida a converter-me em um leitor com vida, que não sente o texto como algo legível, mas como coisa escritível, que eu mesmo movimento, isto é, cujas entradas simbólicas (poética, retórica, economia, psicanálise, política) passarão a depender também de minha sensibilidade, de meu poder de sedução, por exemplo, introduzindo o corpo no intelecto, perturbando a seriedade e a boa consciência do discurso com a paródia. E ainda, na medida em que me invoca o indecifrável da linguagem, mostrando que ela comporta balizas invisíveis, sentidos oblíquos e equívocos. Um poder enigmático que funciona como o suplemento de significação que o intelecto não pode absorver muito bem. Ele consiste na dispersão mesma do significado - que não pode ser expressão de nenhum código -, onde se encontra a origem de todos os mitos. Como também aprendi que as significações sempre são intuídas, que a exorbitante polissemia das significações jamais deixará que elas continuem as mesmas. Enfim, junto a Barthes pude enxergar que as significações se encontram na história, elas são os caminhos das nossas ações e, ainda: são o que de único podemos adjetivar como realidade. 
Albano - E sobre tuas leituras de Bakhtin, o que poderias dizer da carnavalização?

Warat - A literatura carnavalizada apresenta como componente decisivo o contato direto com a vida, e não com a razão. Diria que ela realiza o homem e o mundo simbolicamente, exaltando o "eu" existencial, isto é, não racionalizado. Bakhtin me inspira o coroamento de uma didática carnavalizada com a metamorfose literária em uma profanação epistêmica. Pressinto que estou fazendo um deslocamento da carnavalização para o estudo das relações entre a ciência, o direito e o cotidiano. A carnavalização é uma prática da linguagem que nos propõe, como jogos infantis deslocados, um modo escritível de ter coragem para perseguir as mudanças que perturbam a solidez do meu mundo. O resultado é um conjunto de verdades em trânsito que me ajudaram a entender que a vida, antes de um problema a ser resolvido, é um desejo a ser vivido.

Albano - E sobre o surrealismo bretoniano?

Warat - O que mais me atrai no surrealismo é sua proposta carnavalizada de fundir, pela poesia, os sonhos com a vida. A magia surrealista provoca a leitura emocional, sensitiva, corporal, auditiva e visual do desejo e os sentidos do prazer perdido. O surrealismo convida a ter outra atitude frente ao saber. Mostra que o saber precisa deixar de ser a arquibancada da vida. O futuro do totalitarismo depende de um Tríplice Apocalipse: da natureza, das emoções e da linguagem. No fundo, estou pregando uma volta ao mundo grego, onde a verdade dependia de Eros; a liberdade, do autocontrole; e a beleza, de uma estética da vida.

Albano - Com tais provocações, remetes o leitor para as raízes da cultura ocidental, onde, creio eu, unem-se literatura e poesia, remetendo o conceito de poesia para seu sentido mais amplo, o de poiesis, ou seja, o fazer algo de forma criativa. Concluindo este nosso encontro "encantado", que reflexões nos deixarias?

Warat - Juntar o direito à poesia já é uma provocação surrealista. É o crepúsculo dos deuses do Saber. A queda de suas máscaras rígidas. A morte do maniqueísmo juridicista. Um chamado ao desejo. Um protesto contra a mediocridade da mentalidade erudita, e, ao mesmo 
tempo, um saudável desprezo pelo ensino enquanto ofício. É recriar o homem provocando-o para que procure pertencer-se por inteiro, para que sinta uma profunda aversão contra as infiltrações de uma racionalidade culposa e misticamente objetivista, convertida em "gendarme" da criatividade, do desejo, assim como de nossas ligações com os outros.

A poesia possibilita-lhe isso. Traz em si a visceral compreensão das limitações que padecemos, colocando em evidência a ordem artificial e mortífera de uma cultura impregnada de legalidades presunçosas. Ela pode servir para despertar os sentidos e os desejos soterrados e desencantados por séculos de saberes, preocupados, estes, em garantir todo e qualquer tipo de imobilismo. Praticando a poesia teremos a possibilidade de fazer triunfar o desejo sobre o bom senso e os bons sentimentos, deixando-nos assim, sem ouvidos para os chamados valores nobres e verdadeiros, aqueles que sacralizam, com civismo, o amor ao poder. É o desejo destruindo de um só golpe os Deuses e os Patrões. É a semente da subversão onde menos se espera encontrá-la: a "lanterna mágica do desejo".

Albano - Obrigado por saíres do teu "repouso" e até a próxima charla.

\section{REFERÊNCIAS}

WARAT, Luis Alberto. A ciência jurídica e seus dois maridos: fragmentos de uma expediça $\square$ o pelo direito, pela cien ncia e outros lugares de arrogância. Santa Cruz do Sul: Faculdades Integradas de Santa Cruz do Sul, 1985 .

WARAT, Luis Alberto. Manifesto do surrealismo jurídico. Sa $\square$ o Paulo: Acade mica, 1988.

WARAT, Luis Alberto. Introdução geral ao direito. Porto Alegre: Sérgio Fabris, 1994-1997. 3v.

WARAT, Luis Alberto. Surfando na pororoca: o ofício do mediador. Florianópolis: Fundaça o Boiteux, 2004.

Idioma original: Português

Recebido: 29/12/15

Aceito: 15/02/16 